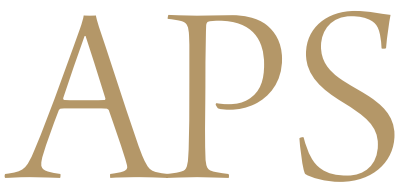

Archives of Plastic Surgery

\title{
Minimal Subdermal Shaving by Means of Sclerotherapy Using Absolute Ethanol: A New Method for the Treatment of Axillary Osmidrosis
}

\author{
Hyung-Sup Shim, Sung-Kee Min, Jin-Soo Lim, Ki-Taik Han, Min-Cheol Kim \\ Department of Plastic and Reconstructive Surgery, St. Vincent's Hospital, The Catholic University of Korea College of Medicine, Suwon, Korea
}

Background Axillary osmidrosis is characterized by unpleasant odors originating from the axillary apocrine glands, resulting in psychosocial stress. The main treatment modality is apocrine gland removal. Until now, of the various surgical techniques have sometimes caused serious complications. We describe herein the favorable outcomes of a new method for ablating apocrine glands by minimal subdermal shaving using sclerotherapy with absolute ethanol.

Methods A total of 12 patients underwent the procedure. The severity of osmidrosis was evaluated before surgery. Conventional subdermal shaving was performed on one side (control group) and ablation by means of minimal subdermal shaving and absolute ethanol on the other side (study group). Postoperative outcomes were compared between the study and control groups.

Results The length of time to removal of the drain was 1 day shorter in the study group than in the control group. There were no serious complications, such as hematoma or seroma, in either group, but flap margin necrosis and flap desquamation occurred in the control group, and were successfully managed with conservative treatment. Six months after surgery, we and our patients were satisfied with the outcomes.

Conclusions Sclerotherapy using absolute ethanol combined with minimal subdermal shaving may be useful for the treatment of axillary osmidrosis. It can reduce the incidence of seroma and hematoma and allow the skin flap to adhere to its recipient site. It can degrade and ablate the remaining apocrine glands and eliminate causative organisms. Furthermore, since this technique is relatively simple, it takes less time than the conventional method.

Keywords Apocrine glands / Axilla / Ethanol / Odors / Sclerotherapy
Correspondence: Min-Cheol Kim Department of Plastic and Reconstructive Surgery, St. Vincent's Hospital, The Catholic University of Korea College of Medicine, 93 Jungbu-daero, Paldal-gu, Suwon 442-723, Korea Tel: +82-31-249-7206 Fax: +82-31-241-0005 E-mail: wisethoth@hotmail.com

This article was presented as a poster at the 3rd Research and Reconstructive Forum on May 9-10, 2013 in Dagu, Korea.

No potential conflict of interest relevant to this article was reported.

Received: 1 Apr 2013 • Revised: 7 May 2013 • Accepted: 24 May 2013

pISSN: 2234-6163 • elSSN: 2234-6171 • http://dx.doi.org/10.5999/aps.2013.40.4.440 • Arch Plast Surg 2013;40:440-444

\section{INTRODUCTION}

Axillary osmidrosis is characterized by unpleasant odors originating from the apocrine glands with hyperhidrosis, that is, excessive and profuse sweating. It is caused by oxidation and hydrolysis of $\varepsilon$-3-methyl 2-hexonoic acid by the normal flora (Staphylococcus aureus and gram negative bacilli) that inhabits the apocrine glands. Fatty acids, proteins, and carbohydrates are sources of $\varepsilon$-3-methyl 2-hexenoic acid. The bacterial metabolic processes are accelerated by emotional stress, exercise, and heat.

Copyright $(\odot 2013$ The Korean Society of Plastic and Reconstructive Surgeons

This is an Open Access article distributed under the terms of the Creative Commons Attribution Non-Commercial License (http://creativecommons.org/

licenses/by-nc/3.0/) which permits unrestricted non-commercial use, distribution, and reproduction in any medium, provided the original work is properly cited. 
If axillary osmidrosis becomes aggravated, it can lead to depression or anxiety and thus result in various negative interpersonal and social impacts [1].

The main treatment modality is to remove the apocrine glands. Until now, there have been a variety of surgical techniques and some recent reports have demonstrated good results using a laser or liposuction. We describe herein a new method for ablating the apocrine glands by means of minimal subdermal shaving and sclerotherapy using absolute ethanol.

\section{METHODS}

\section{Patients}

Between January 2011 and February 2013, a total of 12 patients aged between 15 and 57 years (mean, 26.6 years) underwent our procedure. There were 10 women and 2 men. Unpleasant odors from both axillae were noticed by patients themselves and other persons. The severity of osmidrosis was evaluated by the osmidrosis grading system of Park and Shin [2] before surgery (Table 1). Since axillary hair growth is affected by the presence of apocrine glands, the patients who showed a difference in the quantity of hair growth between the right and left axillae were also excluded from the study. Conventional subdermal shaving was performed on one side (control group), and ablation by means of minimal subdermal shaving and absolute ethanol was performed on the other side (study group). Postoperative outcomes were compared between the control and study groups. The outcomes were estimated by the osmidrosis grading system of Park and Shin and patient satisfaction at least 6 months after surgery (Tables 2, 3).

\section{Table 2. Suction drain removal days and complications}

\begin{tabular}{|c|c|c|c|c|c|}
\hline \multirow{2}{*}{$\begin{array}{c}\text { Patient } \\
\text { No. }\end{array}$} & \multirow{2}{*}{$\begin{array}{l}\text { Sex/ } \\
\text { Age } \\
\text { (yr) }\end{array}$} & \multicolumn{2}{|c|}{ Drain removal day } & \multicolumn{2}{|c|}{ Complication } \\
\hline & & Control & $\begin{array}{l}\text { Sclero- } \\
\text { therapy }\end{array}$ & Control & $\begin{array}{l}\text { Sclero- } \\
\text { therapy }\end{array}$ \\
\hline 1 & $M / 18$ & 5 & 3 & $t^{\text {b) }}$ & - \\
\hline 2 & $F / 15$ & 4 & 3 & & - \\
\hline 3 & $F / 17$ & 5 & 4 & - & - \\
\hline 4 & $F / 18$ & 6 & 5 & - & - \\
\hline 5 & $F / 42$ & 7 & 4 & $t^{c)}$ & - \\
\hline 6 & $F / 15$ & 6 & 5 & - & - \\
\hline 7 & F/33 & 5 & 5 & - & - \\
\hline 8 & $F / 24$ & 4 & 3 & - & - \\
\hline 9 & $\mathrm{~F} / 40$ & 5 & 4 & - & - \\
\hline $10^{\mathrm{a})}$ & $\mathrm{M} / 57$ & 6 & 5 & $t^{\text {b) }}$ & $+^{c)}$ \\
\hline 11 & $F / 18$ & 5 & 5 & - & - \\
\hline 12 & $F / 22$ & 4 & 3 & - & - \\
\hline
\end{tabular}

\section{Table 1. Grading system for the severity of osmidrosis}

\begin{tabular}{|ll}
\hline Grade & \\
\hline 0 & Gauze rubbed on the armpit does not give off any malodor under any circumstances (normal) \\
I & Gauze rubbed on the armpit emits slight malodor only when patients are under stressful conditions (exercising or walking) and no malodor is detected from \\
the rubbed gauze after performing usual daily activities \\
III & Gauze rubbed on the armpit emits strong malodor after performing daily activities but malodor could not be detected at a distance of $1.5 \mathrm{~m}$ from the patient \\
\hline
\end{tabular}

\section{Table 3. Perioperative malodors were evaluated by the grading system}

\begin{tabular}{|c|c|c|c|c|c|c|c|}
\hline \multirow{2}{*}{ Patient No. } & \multirow{2}{*}{$\begin{array}{c}\text { Sex/Age } \\
\text { (yr) }\end{array}$} & \multicolumn{2}{|c|}{ Preoperative Malodor (grade) } & \multicolumn{2}{|c|}{$\begin{array}{l}\text { Postoperative malodor at } \\
\text { follow-up } 6 \text { month (grade) }\end{array}$} & \multicolumn{2}{|c|}{$\begin{array}{l}\text { Patient satisfaction }{ }^{\text {a) }} \text { at } \\
\text { follow-up } 6 \text { month }\end{array}$} \\
\hline & & Control & Sclerotherapy & Control & Sclerotherapy & Control & Sclerotherapy \\
\hline 1 & $\mathrm{M} / 18$ & $\|$ & $\|$ & 0 & 0 & 4 & 4 \\
\hline 2 & $F / 15$ & $\|$ & III & I & 0 & 5 & 5 \\
\hline 3 & $\mathrm{~F} / 17$ & III & III & 0 & 0 & 4 & 5 \\
\hline 4 & $F / 18$ & $\|$ & $\|$ & I & I & 4 & 5 \\
\hline 5 & $\mathrm{~F} / 42$ & III & III & I & । & 3 & 4 \\
\hline 6 & $F / 15$ & $\|$ & $\|$ & I & I & 4 & 5 \\
\hline 7 & $F / 33$ & $\|$ & $\|$ & 0 & 0 & 4 & 4 \\
\hline 8 & $F / 24$ & $\|$ & $\|$ & I & 0 & 4 & 5 \\
\hline 9 & $\mathrm{~F} / 40$ & III & III & I & I & 5 & 5 \\
\hline 10 & $\mathrm{M} / 57$ & $\|$ & $\|$ & I & 0 & 4 & 4 \\
\hline 11 & $F / 18$ & $\|$ & $\|$ & I & 0 & 5 & 5 \\
\hline 12 & $F / 22$ & $\|$ & $\|$ & 0 & 0 & 4 & 4 \\
\hline
\end{tabular}




\section{Operative technique}

In the supine position, both axillae are exposed with the arms abducted about 90 degrees. The area to be treated, which is primarily determined by the distribution of axillary hair growth, is marked. The operative field is routinely prepared with povidoneiodine solution and draped. Local anesthesia is induced using $0.5 \%$ lidocaine mixed with 1:200,000 epinephrine. Thirty to forty milliliters of the anesthetic is used on each side. A 3-cm skin incision is made along the axillary crease (Fig. 1). The marked area is subdermally undermined with curved scissors. It is not necessary to resect all of the apocrine glands as in conventional method, but the apocrine glands should be sufficiently dissected for flap preparation (Fig. 2). The wound is irrigated with normal saline and bleeding is meticulously controlled. A suction drain is inserted into the operation site and the wound is closed. The midportion of the skin flap is anchored to the axillary fascia with a 5-0 Vicryl sutures to minimize dead space. After skin closure

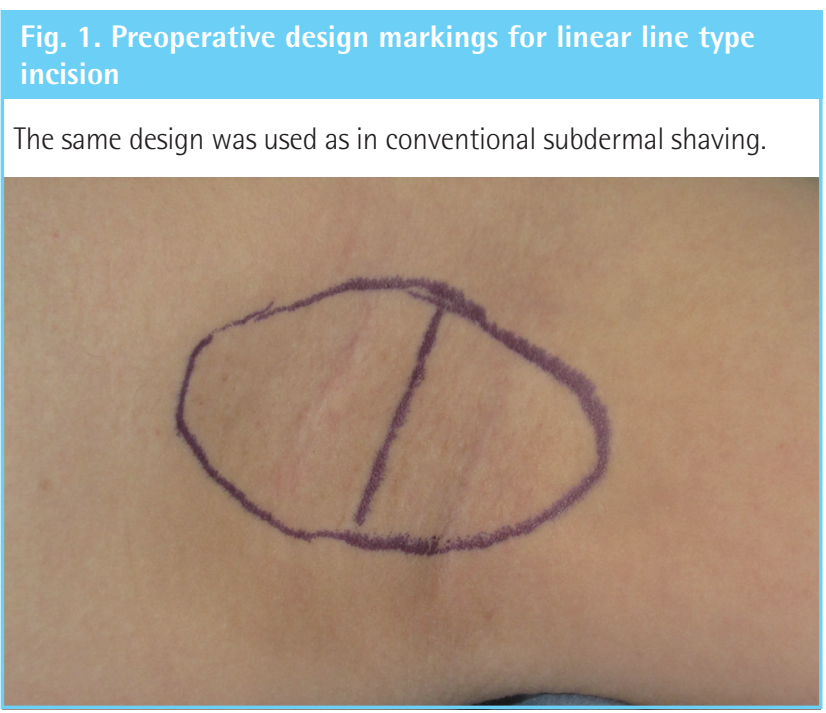

\section{Fig. 2. Photograph after minimal subdermal shaving}

The apocrine glands were exposed and minimal shaving was performed, with the subdermal plexus being left neither damaged nor compromised.

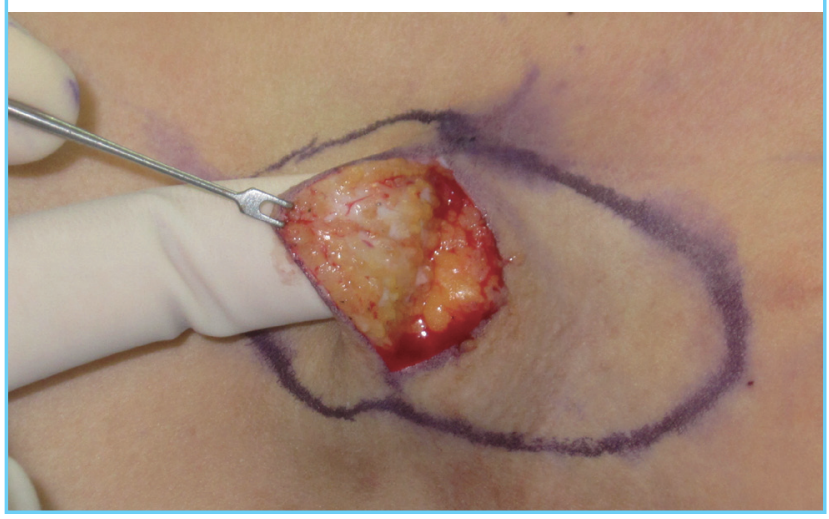

with 5-0 black silk, a moderate amount of absolute alcohol is injected so as not to disrupt the wound via the suction drain tube for 60 seconds and then drained off (Fig. 3). This ethanol injection and drainage procedure is repeated 3 times. After injections, a drain bag is attached to the same suction tube. The treated area is covered with gauze and minimal compressive dressing. All of the patients are instructed to minimize their arm movements as much as possible, especially during the first 2 postoperative days. All of the stitches are removed 10 days after surgery.

\section{RESULTS}

The suction drain was removed when the drained fluid was less than $5 \mathrm{~mL}$ per 24 hours. The length of time to drain removal was 1.09 days shorter in the study group (mean, 4.08 days) than in the control group (mean, 5.17 days). There were no serious complications, such as hematoma or seroma in the study and control groups, but flap margin necrosis and flap desquamation occurred in 2 patients each in the control group, and were successfully managed with conservative treatment. One patient had partial skin necrosis on the control side and skin desquamation on the study side. This patient was a heavy smoker who showed poor compliance with postoperative instructions. Nevertheless, the wound completely healed within 1 month after conservative treatment. Six months after surgery, the objective outcomes were very good and the patients were satisfied with the outcomes (Tables 2, 3).

\section{DISCUSSION}

The human axilla produces a characteristic odor called an "axillary odor." In the axilla, various compounds are secreted by

\section{Fig. 3. Ethanol sclerotherapy performed through suction drainage}

A suction drain inserted into the incision site with wound closure and absolute ethanol used for sclerotherapy.

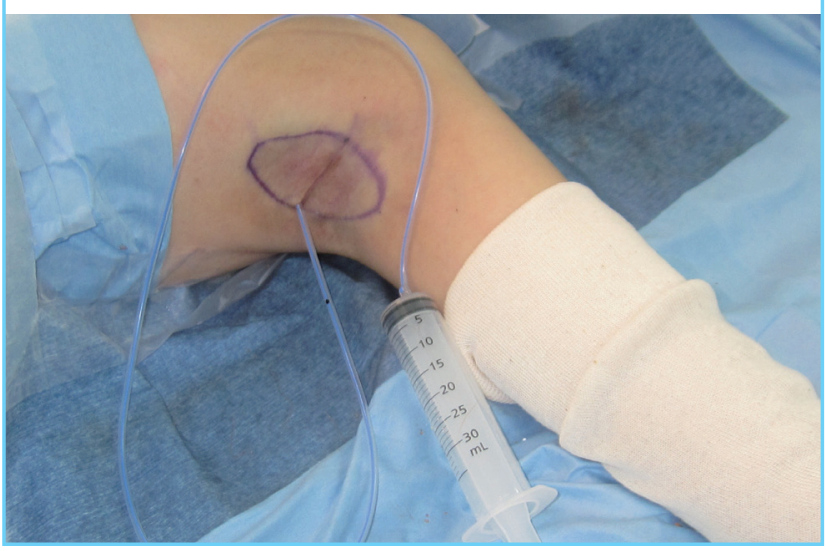


many types of glands, such as apocrine, eccrine, and sebaceous glands. The axillary odor is caused by interactions between apocrine secretions and the normal flora of the axilla.

There have been numerous studies on axillary odor in terms of chemistry, gender differences, intensity, and related microorganisms. In addition, $\varepsilon$-3-methyl 2-hexenoic acid has been identified as an axillary odor-related compound, which is secreted by the axillary apocrine glands in Caucasians. Akutsu et al. [1] analyzed $\varepsilon$-3-methyl 2-hexenoic acid from individually collected axillary sweat and reported that $\varepsilon$-3-methyl 2-hexenoic acid is also found in the axillary sweat of Asians. Rennie et al. [3] demonstrated that Corynebacterium species produce odor in the axillary region and that the axillary microflora is specifically involved in underarm odor production.

Numerous treatment methods for axillary osmidrosis have been introduced. Hurley et al. [4] reported en bloc excision of the axillary skin and soft tissue. Inaba et al. [5] introduced selective surgical excision of the apocrine and eccrine glands, which has become one of the most popular surgical methods. We called this surgical method "conventional subdermal shaving" in our study. Alternatively, suction curettage with mechanical liposuction cannulas or ultrasonic suction instruments is also a well known method. Recently, many centers have reported methods for treating axillary osmidrosis with lasers, including $\mathrm{CO}_{2}$ and Nd-Yag lasers [6]; however, conventional subdermal shaving is still the treatment of choice [2]. Previous studies have reported complications of the subdermal shaving method, including hematoma, seroma, skin flap necrosis, wound infection, and the recurrence of malodor [2]. These complications are caused by failure to control microbleeding, subdermal plexus injury due to aggressive shaving, contamination with the normal flora, and remnant apocrine glands. Like a double-edged sword, aggressive shaving for the removal of apocrine glands can increase the possibility of subdermal plexus injury, while minimal shaving in order to avoid subdermal plexus injury can lead to recurrence of osmidrosis due to remnant apocrine glands. To avoid these complications, alternative options, such as the use of tumescent solution and tie-over compression [7] have been introduced. Many authors have reported performing these alternative methods to avoid the possible complications mentioned above.

The chemical, physiologic, biochemical nature of sclerosants deforms the target tissue, whose byproducts induce cell damage, fibroblast proliferation, and sclerosis. In addition, thrombosis, protein extraction from lipids, protein denaturation, cell dehydration, and physical obstruction by polymerization impair functions of the target tissue [8]. Ethanol was first described as a sclerosant in a canine renal model in the 1980s [9]. Its mechanisms of action include the denaturation and extraction of surface proteins, cell dehydration, coagulation, thrombosis, and fibrinoid necrosis [10-12]. Its effectiveness is related to the concentration, exposure time, and injection speed [13].

Sclerotherapy using ethanol has been widely used in the treatment of esophageal piles, vascular malformations, varicose veins, and benign cysts, such as thyroglossal cysts, renal cysts, and ovarian endometriomas. It has recently been used for the treatment of chronic recurrent ischial pressure sores following surgical treatment [14] and rheumatoid bursal cysts [15]. Absolute ethanol causes damage to the endothelial cells in abnormal vessels, sterilizes the environment by its bactericidal effect, and alters the subcutaneous layer by coagulation as well as tissue modification of cell proteins. Since absolute ethanol causes tissue conglutination and obliteration of the dead space, it has been widely used to treat cavitary disease. Systemic side effects are rare unless absolute ethanol is directly injected into blood vessels [14]. Absolute ethanol has rarely been reported as a cause of hypersensitivity. In a previous study, absolute alcohol skin prick test results were negative in all patients who showed allergic reactions after alcohol intake [16].

Our surgical procedure minimized subdermal plexus injury by using less aggressive shaving than the conventional method. For this reason, the frequency of complications, such as skin necrosis, desquamation, and wound disruption, decreased. Discharge from the operation site also decreased and resulted in earlier drain removal by 1.09 days than the conventional method. Complications, such as hematoma and seroma, were not seen in the study group. Postoperative satisfaction was similar in the study and control groups. Other late complications, including recurrence of osmidrosis, hypertrophic scar formation, and limitation of shoulder movement, did not occur in the study group over a 6-month follow-up period.

Sclerotherapy combined with minimal subdermal shaving may be useful for treating axillary osmidrosis through several mechanisms. First, absolute ethanol can reduce the incidence of seroma and hematoma by coagulation, cell modification, and obliteration of dead space. Furthermore, it allows the skin flap to adhere to its recipient site. Second, as a result of its cytotoxicity, unrecognized remnant apocrine glands can be degraded and ablated. Because of its apocrine gland ablation effect, surgeons do not need to perform excessive surgical removal of the subdermal layer, leading to preservation of the subdermal plexus, which allows for better skin flap survival. Additionally, owing to its bactericidal effect, absolute ethanol can eliminate causative organisms which colonize the normal axillary skin. Lastly, the sclerotherapy is relatively simple and requires a shorter operation time than the conventional method. As a result, a low complication rate and early recovery following earlier drain removal 
was shown.

This study has some limitations. First, the small number of cases limits statistical analysis. Second, the severity of osmidrosis could differ between the two axillae before surgery, which may be a confounding factor. Third, follow-up longer than 2 years was not feasible, and therefore we were not able to check for scar tissue formation or late recurrence. Fourth, we could not perform histopathologic studies because it was difficult to obtain consent from each patient, and the wounds healed well without any complications. Despite these limitations, our method may be effective in treating patients with axillary odors, and was easy to perform with a low complication rate.

\section{REFERENCES}

1. Akutsu T, Sekiguchi K, Ohmori T, et al. Individual comparisons of the levels of (E)-3-methyl-2-hexenoic acid, an axillary odor-related compound, in Japanese. Chem Senses 2006;31:557-63.

2. Park YJ, Shin MS. What is the best method for treating osmidrosis? Ann Plast Surg 2001;47:303-9.

3. Rennie PJ, Gower DB, Holland KT. In-vitro and in-vivo studies of human axillary odour and the cutaneous microflora. Br J Dermatol 1991;124:596-602.

4. Hurley HJ, Shelley WB. A Simple Surgical Approach to the Management of Axillary Hyperidrosis. JAMA 1963;186: 109-12.

5. Inaba M, Anthony J, Ezaki T. Radical operation to stop axillary odor and hyperhidrosis. Plast Reconstr Surg 1978;62: 355-60.

6. Kim D, Kim J, Yeo H, et al. Treatment of Axillary Osmidrosis Using a Subcutaneous Pulsed Nd-YAG Laser. Arch Plast Surg
2012;39:143-9.

7. Miyamoto E, Hayashi A, Komoto M, et al. "Sea anemoneshaped fixation": a feasible tie-over technique for axillary osmidrosis. J Plast Reconstr Aesthet Surg 2012;65:e202-3.

8. Albanese G, Kondo KL. Pharmacology of sclerotherapy. Semin Intervent Radiol 2010;27:391-9.

9. Becker GH, Holden RW, Heun YY, et al. Ablation with absolute alcohol. In: Castaneda-Zuniga WR, Tadavarthy SM, editors. Interventional radiology. Baltimore: Williams and Wilkins; 1992. p.135-52.

10. Ellman BA, Green CE, Eigenbrodt E, et al. Renal infarction with absolute ethanol. Invest Radiol 1980;15:318-22.

11. Do YS, Yakes WF, Shin SW, et al. Ethanol embolization of arteriovenous malformations: interim results. Radiology 2005;235:674-82.

12. Mourao GS, Hodes JE, Gobin YP, et al. Curative treatment of scalp arteriovenous fistulas by direct puncture and embolization with absolute alcohol. Report of three cases. J Neurosurg 1991;75:634-7.

13. Ellman BA, Parkhill BJ, Marcus PB, et al. Renal ablation with absolute ethanol. Mechanism of action. Invest Radiol 1984;19:416-23.

14. Hayashi T, Honda K, Kimura C, et al. Treatment of ischial pressure sores by means of sclerotherapy using absolute ethanol. Ann Plast Surg 2004;53:554-9.

15. Hayashi A, Matsumura T, Komoto M, et al. Multiple rheumatoid bursal cysts that were finally effectively treated by combining surgical resection and sclerotherapy. J Plast Reconstr Aesthet Surg 2012;65:e29-32.

16. Ehlers I, Hipler UC, Zuberbier T, et al. Ethanol as a cause of hypersensitivity reactions to alcoholic beverages. Clin Exp Allergy 2002;32:1231-5. 